\section{NUCLEAR REGULATORY COMMISSION}

[Docket No. 50-391; NRC-2008-0369]

\section{Tennessee Valley Authority; Notice of Receipt of Update to Application for Facility Operating License and Notice of Opportunity for Hearing for the Watts Bar Nuclear Plant, Unit 2 and Order Imposing Procedures for Access to Sensitive Unclassified Non- Safeguards Information and Safeguards Information for Contention Preparation}

In accordance with the Commission's direction in its Staff Requirements Memorandum SECY-07-0096, "Staff Requirements-Possible Reactivation of Construction and Licensing Activities for the Watts Bar Nuclear Plant Unit 2," dated July 25, 2007, and pursuant to the Atomic Energy Act of 1954 (the Act), as amended, and the regulations in Title 10 of the Code of Federal Regulations (10 CFR) Part 2, "Rules of Practice for Domestic Licensing Proceedings and Issuance of Orders,"' and 10 CFR Part 50, "Domestic Licensing of Production and Utilization Facilities," notice is hereby given that, on March 4, 2009, the U.S. Nuclear Regulatory Commission (NRC, the Commission) has received an update to the application for a facility operating license (OL) from the Tennessee Valley Authority (TVA or the applicant) that would authorize TVA to possess, use, and operate a second lightwater nuclear reactor (the facility), Watts Bar Nuclear Plant (WBN) Unit 2, located on the applicant's site in Rhea County, Tennessee. The unit would operate at a steady-state power level of 3,411 megawatts thermal. The original application dated June 30, 1976, was found acceptable for docketing on September 15, 1976, and "Notice of Receipt of Application for Facility Operating Licenses; Notice of Consideration of Issuance of Facility Operating Licenses; and Notice of Opportunity for Hearing" for WBN Units 1 and 2 was published in the Federal Register on December 27, 1976 (41 FR 56244). On February 7, 1996, the NRC issued a full-power OL to TVA to operate WBN Unit 1 at this site. However, TVA has not completed construction of WBN Unit 2. Construction of the facility was authorized by Construction Permit No. CPPR-92, issued by the Commission on January 23, 1973. TVA has stated that it expects to complete construction prior to April 1, 2012.

Pursuant to the National

Environmental Policy Act, as amended, and the Commission's regulations in 10 CFR Part 51, on February 15, 2008, TVA submitted to the NRC "Watts Bar Nuclear Plant (WBN)-Unit 2-Final Supplemental Environmental Impact Statement [FSEIS] for the Completion and Operation of Unit 2," to the NRC in support of its OL application for WBN Unit 2. By letter dated January 27, 2009, TVA submitted its "Final Supplemental Environmental Impact StatementSevere Accident Management Alternatives [SAMA]," to supplement its FSEIS. After the staff has completed its review of TVA's FSEIS, the NRC will prepare a draft supplement to environmental impact statement related to the operation of WBN Unit 2 (SEISOL). Upon preparation of the draft SEIS-OL, the Commission will, among other things, cause to be published in the Federal Register, a notice of availability of the draft supplement, requesting comments from interested persons on the draft SEIS-OL. The notice will also contain a statement to the effect that any comments of Federal agencies and State and local officials will be made available when received. The draft SEIS-OL will focus on matters that differ from those previously discussed in the final environmental statement prepared in connection with the issuance of the construction permits and the WBN Unit 1 OL. Upon consideration of comments submitted with respect to the draft SEIS-OL, the Commission's staff will prepare a final SEIS-OL, the availability of which will be published in the Federal Register.

The NRC staff will complete a detailed technical review of the application and will document its findings in Supplements to NUREG0847, "Safety Evaluation Report Related to the Operation of Watts Bar Nuclear Plant, Unit 2.,

The Commission will consider the issuance of the facility OL to TVA, which would authorize the applicant to possess, use and operate the WBN Unit 2 in accordance with the provisions of the license and the technical

specifications appended thereto, upon: (1) The completion of a favorable safety evaluation of the application by the Commission's staff; (2) the completion of the environmental review required by the Commission's regulations in $10 \mathrm{CFR}$ Part 51; (3) the receipt of a report on the applicant's application for the facility OL by the Advisory Committee on Reactor Safeguards; and (4) a finding by the Commission that the application for the facility licenses, as amended, complies with the requirements of the Atomic Energy Act of 1954, as amended (the Act), and the Commission's regulations in 10 CFR Chapter I.

The OL will not be issued until the Commission has made the findings reflecting its review of the application under the Act, which will be set forth in the proposed license, and has concluded that the issuance of the license will not be inimical to the common defense and security or to the health and safety of the public.

Within 60 days after the date of initial publication of this notice in the Federal Register on May 1, 2009 (74 FR 20350), any person(s) whose interest may be affected by this action and who desires to participate as a party to this action may file a written request for a hearing and a petition to intervene with respect to whether an OL should be issued. Requests for a hearing and a petition for leave to intervene shall be filed in accordance with the Commission's "Rules of Practice for Domestic Licensing Proceedings" in 10 CFR Part 2.

Interested person(s) should consult a current copy of 10 CFR 2.309, "Hearing Requests, Petitions To Intervene, Requirements for Standing, and Contentions," which is available at the Commission's Public Document Room (PDR), located at One White Flint North, Public File Area O-1F21, 11555 Rockville Pike (first floor), Rockville, Maryland. Publicly available records will be accessible from the Agencywide Documents Access and Management System (ADAMS) Public Electronic Reading Room on the internet at the NRC Web site, http://www.nrc.gov/ reading-rm/doc-collections/cfr/. Although the notice of the application will be published once each week for 4 consecutive weeks in the Federal Register, the 60-day period will only begin upon the date of the first publication of the notice.

If a request for a hearing or petition for leave to intervene is filed within 60 days of the date of the initial notice, the Commission or a presiding officer designated by the Commission or by the Chief Administrative Judge of the Atomic Safety and Licensing Board Panel, will rule on the request and/or petition; and the Secretary or the Chief Administrative Judge of the Atomic Safety and Licensing Board will issue a notice of a hearing or an appropriate order.

As required by 10 CFR 2.309, a petition for leave to intervene or request for hearing shall set forth with particularity the interest of the petitioner/requestor in the proceeding, and how that interest may be affected by the results of the proceeding. The petition should specifically explain the reasons why intervention should be permitted with particular reference to the following general requirements: (1) The name, address and telephone 
number of the requestor or petitioner; (2) the nature of the requestor's/ petitioner's right under the Act to be made a party to the proceeding; (3) the nature and extent of the requestor's/ petitioner's property, financial, or other interest in the proceeding; and (4) the possible effect of any decision or order which may be entered in the proceeding on the requestor's/petitioner's interest. The petition must also identify the specific contentions which the petitioner/requestor seeks to have litigated at the proceeding.

Each contention must consist of a specific statement of the issue of law or fact to be raised or controverted. In addition, the petitioner/requestor shall provide a brief explanation of the bases for the contention and a concise statement of the alleged facts or expert opinion which support the contention and on which the petitioner intends to rely in proving the contention at the hearing. The petitioner/requestor must also provide references to those specific sources and documents of which the petitioner is aware and on which the petitioner intends to rely to establish those facts or expert opinion. The petition must include sufficient information to show that a genuine dispute exists with the applicant on a material issue of law or fact.

Contentions shall be limited to matters within the scope of the licensing action under consideration. The scope of the hearing and intervention request is limited to TVA's application for an OL. The contention must be one which, if proven, would entitle the petitioner/ requestor to relief. A petitioner/ requestor who fails to satisfy these requirements with respect to at least one contention will not be permitted to participate as a party.

Those permitted to intervene shall become parties to the proceeding, subject to any limitations in the order granting leave to intervene, and have the opportunity to participate fully in the conduct of the hearing.

All documents filed in NRC adjudicatory proceedings, including a request for hearing, a petition for leave to intervene, any motion or other document filed in the proceeding prior to the submission of a request for hearing or petition to intervene, and documents filed by interested governmental entities participating under 10 CFR 2.315(c), must be filed in accordance with the NRC E-Filing rule, which the NRC promulgated on August 28, 2007 (72 FR 49139). The E-Filing process requires participants to submit and serve all adjudicatory documents over the Internet, or in some cases to mail copies on electronic storage media.
Participants may not submit paper copies of their filings unless they seek a waiver in accordance with the procedures described below.

To comply with the procedural requirements associated with E-Filing, at least 10 days prior to the filing deadline, the requestor should contact the Office of the Secretary by e-mail at hearing.docket@nrc.gov or by calling (301) 415-1677, to request (1) a digital identification (ID) certificate that allows the participant (or its counsel or representative) to digitally sign documents and access the E-Submittal server for any NRC proceeding in which it is participating or (2) the creation of an electronic docket for the proceeding (even in instances when the requestor (or its counsel or representative) already holds an NRC-issued digital ID certificate). Each requestor will need to download the Workplace Forms ViewerTM to access the Electronic Information Exchange (EIE) viewer, which is a component of the E-Filing system. The Workplace Forms Viewer ${ }^{\mathrm{TM}}$ is free and is available at http:// www.nrc.gov/site-help/e-submittals/ install-viewer.html. Information about how to apply for a digital ID certificate is also available on NRC's public Web site at http://www.nrc.gov/site-help/esubmittals/apply-certificates.html.

Once a petitioner/requestor has obtained a digital ID certificate, had a docket created, and downloaded the EIE viewer, he or she can then submit a request for a hearing through EIE. Submissions should be in portable document format (PDF) in accordance with NRC guidance available on the NRC public Web site at http:// www.nrc.gov/site-help/e-

submittals.html. A filing is considered complete at the time the filer submits the document through EIE. To be timely, electronic filings must be submitted to the EIE system no later than 11:59 p.m. eastern time on the due date. Upon receipt of a transmission, the E-Filing system time-stamps the document and sends the submitter an e-mail notice confirming receipt of the document. The EIE system also distributes an e-mail notice that provides access to the document to the NRC Office of the General Counsel and any others who have advised the Office of the Secretary that they wish to participate in the proceeding, so that the filer need not serve the document on those participants separately. Therefore, applicants and other participants (or their counsel or representative) must apply for and receive a digital ID certificate before a hearing request is filed so that they may obtain access to the document via the E-Filing system.
A person filing electronically using the agency's adjudicatory e-filing system may seek assistance through the "Contact Us" link located on the NRC Web site at http://www.nrc.gov/sitehelp/e-submittals.html or by calling the NRC Electronic Filing Help Desk, which is available between 8 a.m. and 8 p.m., eastern time, Monday through Friday, excluding government holidays. The toll-free help line number is (866) 6727640. A person filing electronically may also seek assistance by sending an email to the NRC Electronic Filing Help Desk at MSHD.resource@nrc.gov.

Participants who believe that they have good cause for not submitting documents electronically must file an exemption request, in accordance with 10 CFR 2.302(g), with their initial paper filing requesting authorization to continue to submit documents in paper format. Such filings must be submitted (1) by first-class mail addressed to the Office of the Secretary of the Commission, U.S. Nuclear Regulatory Commission, Washington, DC 205550001, Attention: Rulemaking and Adjudications Staff, or (2) by courier, express mail, or expedited delivery service to the Office of the Secretary, Sixteenth Floor, One White Flint North, 11555 Rockville Pike, Rockville, Maryland 20852, Attention: Rulemaking and Adjudications Staff. Participants filing a document in this manner are responsible for serving the document on all other participants. Filing is considered complete by first-class mail as of the time of the deposit in the mail, or by courier, express mail, or expedited delivery service upon depositing the document with the provider of the service.

Non-timely requests and/or petitions and contentions will not be entertained absent a determination by the Commission or the presiding officer of the Atomic Safety and Licensing Board that the petition and/or request should be granted and/or the contentions should be admitted based on a balancing of the factors specified in 10 CFR 2.309(c)(1)(i)-(viii). To be timely, filings must be submitted no later than 11:59 p.m. eastern time on the due date.

Documents submitted in adjudicatory proceedings will appear in NRC's electronic hearing docket which is available to the public at http:// ehd.nrc.gov/EHD_Proceeding/home.asp, unless they are excluded under an order of the Commission, the Atomic Safety and Licensing Board, or a presiding officer. Participants are requested not to include personal privacy information such as social security numbers, home addresses, or home telephone numbers in their filings. With respect to 
copyrighted works, except for limited excerpts that serve the purpose of the adjudicatory filings and would constitute a "fair use" application, participants are requested not to include copyrighted materials in their

submission.

For further details pertinent to the matters under consideration, see the application for the facility OL dated June 30, 1975, as supplemented on September 27, 1976, and as updated on March 4, 2009, which are available for public inspection at the Commission's PDR, located at One White Flint North, Public File Area O1F21, 11555

Rockville Pike (first floor), Rockville, Maryland. Publicly available records will be accessible electronically through the ADAMS Public Electronic Reading Room link on the internet at the NRC Web site http://www.nrc.gov/readingrm/adams.html. Certain documents included in the OL application contain sensitive unclassified non-safeguards information and safeguards information. Persons who do not have access to ADAMS or who encounter problems in accessing documents located in ADAMS should contact the NRC PDR Reference staff by telephone at 1-800-4209, 301415-4737, or by e-mail to pdr.resources@nrc.gov. The OL application and its supplement and update are available at $h t t p: / /$ www.nrc.gov/reactors/plant-specificitems/watts-bar.html. The ADAMS accession numbers for the OL application cover letter and supplement cover letter are ML073400595 and ML073381112, respectively. The ADAMS accession number for the update to the application is ML090700378. The ADAMS accession number for Supplement 21 to NUREG0847 is ML090570741. The ADAMS accession number for the final safety analysis report, as redacted under 10 CFR 2.390(d)(1), is ML090980525. The redactions were made in compliance with the NRC's criteria on sensitive information, as specified in SECY-040191, "Withholding Sensitive Unclassified Information Concerning Nuclear Power Reactors From Public Disclosure," dated October 19, 2004 (ADAMS accession number ML042310663), as modified by the NRC Commission Staff Requirements Memorandum SECY-04-0191, dated November 9, 2004 (ADAMS accession number ML043140175). To search for other related documents in ADAMS using the Watts Bar Nuclear Plant Unit 2 OL application docket number, 50391, enter the term "05000391" in the "Docket Number" field when using either the Web-based search (advanced search) engine or the ADAMS find tool in Citrix.

Attorney for the applicant: Maureen H. Dunn, Executive Vice President and General Counsel, Tennessee Valley Authority, 400 West Summit Hill Drive, Knoxville, TN 37902.

Order Imposing Procedures for Access to Sensitive Unclassified NonSafeguards Information (SUNSI) and Safeguards Information (SGI) for Contention Preparation, Tennessee Valley Authority Watts Bar Nuclear Plant, Unit 2, Located in Rhea County, Tennessee

[Docket No. 50-391]

1.This order contains instructions regarding how potential parties to the proceedings listed above may request access to documents containing sensitive unclassified non-safeguards information and safeguards information (SUNSI and SGI).

2. Within ten (10) days after publication of this notice of opportunity for hearing, any potential party as defined in 10 CFR 2.4 who believes access to SUNSI or SGI is necessary for a response to the notice may request access to SUNSI or SGI. A "potential party" is any person who intends or may intend to participate as a party by demonstrating standing and the filing of an admissible contention under 10 CFR 2.309. Requests submitted later than ten (10) days will not be considered absent a showing of good cause for the late filing, addressing why the request could not have been filed earlier.

3 . The requester shall submit a letter requesting permission to access SUNSI and/or SGI to the Office of the Secretary, U.S. Nuclear Regulatory Commission, Washington, DC 20555-0001, Attention: Rulemakings and Adjudications Staff, and provide a copy to the Associate General Counsel for Hearings,

Enforcement and Administration, Office of the General Counsel, Washington, DC 20555-0001. The expedited delivery or courier mail address for both offices is U.S. Nuclear Regulatory Commission, 11555 Rockville Pike, Rockville, MD 20852. The e-mail addresses for the Office of the Secretary and the Office of the General Counsel are hearing.docket@nrc.gov and ogcmailcenter.resource@nrc.gov, respectively. ${ }^{1}$ The request must include the following information:

a. A description of the licensing action with a citation to this Federal

\footnotetext{
${ }^{1}$ While a request for hearing or petition to intervene in this proceeding must comply with the filing requirements of the NRC's "E-Filing Rule," the initial request to access SUNSI and/or SGI under these procedures should be submitted as described in this paragraph.
}

Register notice of opportunity for hearing;

b. The name and address of the potential party and a description of the potential party's particularized interest that could be harmed by the action identified in (a);

c. If the request is for SUNSI, the identity of the individual requesting access to SUNSI and the requester's need for the information in order to meaningfully participate in this adjudicatory proceeding, particularly why publicly available versions of the application would not be sufficient to provide the basis and specificity for a proffered contention;

d. If the request is for SGI, the identity of the individual requesting access to SGI and the identity of any expert, consultant or assistant who will aid the requester in evaluating the SGI, and information that shows:

(i) Why the information is indispensable to meaningful participation in this licensing proceeding; and

(ii) The technical competence (demonstrable knowledge, skill, experience, training or education) of the requester to understand and use (or evaluate) the requested information to provide the basis and specificity for a proffered contention. The technical competence of a potential party or its counsel may be shown by reliance on a qualified expert, consultant or assistant who demonstrates technical competence as well as trustworthiness and reliability, and who agrees to sign a nondisclosure affidavit and be bound by the terms of a protective order; and

e. If the request is for SGI, Form SF-

85, "Questionnaire for Non-Sensitive Positions," Form FD-258 (fingerprint card), and a credit check release form completed by the individual who seeks access to SGI and each individual who will aid the requester in evaluating the SGI. For security reasons, Form SF-85 can only be submitted electronically, through a restricted-access database. To obtain online access to the form, the requester should contact the NRC's Office of Administration at 301-492$3524 .^{2}$ The other completed forms must be signed in original ink, accompanied by a check or money order payable in the amount of $\$ 200.00$ to the U.S. Nuclear Regulatory Commission for each individual, and mailed to the: Office of Administration, Security Processing Unit, Mail Stop TWB-05

\footnotetext{
${ }^{2}$ The requester will be asked to provide his or her full name, social security number, date and place of birth, telephone number, and e-mail address. After providing this information, the requester usually should be able to obtain access to the online form within one business day.
} 
B32M, U.S. Nuclear Regulatory Commission, Washington, DC 205550012.

These forms will be used to initiate the background check, which includes fingerprinting as part of a criminal history records check. Note: copies of these forms do not need to be included with the request letter to the Office of the Secretary, but the request letter should state that the forms and fees have been submitted as described above.

4. To avoid delays in processing requests for access to SGI, all forms should be reviewed for completeness and accuracy (including legibility) before submitting them to the NRC. Incomplete packages will be returned to the sender and will not be processed.

5 . Based on an evaluation of the information submitted under items 2 and 3.a through 3.d, above, the NRC staff will determine within ten days of receipt of the written access request whether (1) there is a reasonable basis to believe the petitioner is likely to establish standing to participate in this NRC proceeding, and (2) there is a legitimate need for access to SUNSI or need to know the SGI requested. For SGI, the need to know determination is made based on whether the information requested is necessary (i.e., indispensable) for the proposed recipient to proffer and litigate a specific contention in this NRC proceeding ${ }^{3}$ and whether the proposed recipient has the technical competence (demonstrable knowledge, skill, training, education, or experience) to evaluate and use the specific SGI requested in this proceeding.

6. If standing and need to know SGI are shown, the NRC staff will further determine based upon completion of the background check whether the proposed recipient is trustworthy and reliable. The NRC staff will conduct (as necessary) an inspection to confirm that the recipient's information protection systems are sufficient to protect SGI from inadvertent release or disclosure. Recipients may opt to view SGI at the NRC's facility rather than establish their own SGI protection program to meet SGI protection requirements.

7. A request for access to SUNSI or SGI will be granted if:

a. The request has demonstrated that there is a reasonable basis to believe that

\footnotetext{
${ }^{3}$ Broad SGI requests under these procedures are thus highly unlikely to meet the standard for need to know; furthermore, staff redaction of information from requested documents before their release may be appropriate to comport with this requirement. These procedures do not authorize unrestricted disclosure or less scrutiny of a requester's need to know than ordinarily would be applied in connection with an already-admitted contention.
}

a potential party is likely to establish standing to intervene or to otherwise participate as a party in this proceeding;

b. The proposed recipient of the information has demonstrated a need for SUNSI or a need to know for SGI, and that the proposed recipient of SGI is trustworthy and reliable;

c. The proposed recipient of the information has executed a NonDisclosure Agreement or Affidavit and agrees to be bound by the terms of a Protective Order setting forth terms and conditions to prevent the unauthorized or inadvertent disclosure of SUNSI and/ or SGI; and

$\mathrm{d}$. The presiding officer has issued a protective order concerning the information or documents requested. ${ }^{4}$ Any protective order issued shall provide that the petitioner must file SUNSI or SGI contentions 25 days after receipt of (or access to) that information. However, if more than 25 days remain between the petitioner's receipt of (or access to) the information and the deadline for filing all other contentions (as established in the notice of hearing or opportunity for hearing), the petitioner may file its SUNSI or SGI contentions by that later deadline.

8 . If the request for access to SUNSI or SGI is granted, the terms and conditions for access to sensitive unclassified information will be set forth in a draft protective order and affidavit of non-disclosure appended to a joint motion by the NRC staff, any other affected parties to this

proceeding, ${ }^{5}$ and the petitioner(s). If the diligent efforts by the relevant parties or petitioner(s) fail to result in an agreement on the terms and conditions for a draft protective order or nondisclosure affidavit, the relevant parties to the proceeding or the petitioner(s) should notify the presiding officer within ten (10) days, describing the obstacles to the agreement.

9. If the request for access to SUNSI is denied by the NRC staff or a request for access to SGI is denied by NRC staff either after a determination on standing and need to know or, later, after a determination on trustworthiness and reliability, the NRC staff shall briefly state the reasons for the denial. Before the Office of Administration makes an

${ }^{4}$ If a presiding officer has not yet been designated, the Chief Administrative Judge will issue such orders, or will appoint a presiding officer to do so.

${ }^{5}$ Parties/persons other than the requester and the NRC staff will be notified by the NRC staff of a favorable access determination (and may participat in the development of such a motion and protective order) if it concerns SUNSI and if the party/person' interest independent of the proceeding would be harmed by the release of the information (e.g., as with proprietary information) adverse determination regarding access, the proposed recipient must be provided an opportunity to correct or explain information. The requester may challenge the NRC staff's adverse determination with respect to access to SUNSI or with respect to standing or need to know for SGI by filing a challenge within ten (10) days of receipt of that determination with (a) the presiding officer designated in this proceeding; (b) if no presiding officer has been appointed, the Chief Administrative Judge, or if he or she is unavailable, another administrative judge, or an administrative law judge with jurisdiction pursuant to 10 CFR 2.318(a); or (c) if another officer has been designated to rule on information access issues, with that officer. In the same manner, an SGI requester may challenge an adverse determination on trustworthiness and reliability by filing a challenge within fifteen (15) days of receipt of that determination.

In the same manner, a party other than the requester may challenge an NRC staff determination granting access to SUNSI whose release would harm that party's interest independent of the proceeding. Such a challenge must be filed within ten (10) days of the notification by the NRC staff of its grant of such a request.

If challenges to the NRC staff determinations are filed, these procedures give way to the normal process for litigating disputes concerning access to information. The availability of interlocutory review by the Commission of orders ruling on such NRC staff determinations (whether granting or denying access) is governed by 10 CFR $2.311 .^{6}$

10. The Commission expects that the NRC staff and presiding officers (and any other reviewing officers) will consider and resolve requests for access to SUNSI and/or SGI, and motions for protective orders, in a timely fashion in order to minimize any unnecessary delays in identifying those petitioners who have standing and who have propounded contentions meeting the specificity and basis requirements in 10 CFR Part 2. Attachment 1 to this Order summarizes the general target schedule for processing and resolving requests under these procedures.

\footnotetext{
${ }^{6}$ As of October 15, 2007, the NRC's final "EFiling Rule” became effective. See Use of Electronic Submissions in Agency Hearings (72 FR 49139; Aug. 28, 2007). Requesters should note that the filing requirements of that rule apply to appeals of NRC staff determinations (because they must be served on a presiding officer or the Commission, as applicable), but not to the initial SUNSI/SGI requests submitted to the NRC staff under these procedures.
} 
Dated at Rockville, Maryland, this 1st day of May 2009.
For the Nuclear Regulatory Commission.

Annette L. Vietti-Cook,

Secretary of the Commission.

Attachment 1-General Target Schedule for Processing and Resolving ReQUests for Access to Sensitive UNCLASSIFIED NON-SAFEGUARDS INFORMATION (SUNSI) AND SAFEGUARDS INFORMATION (SGI) IN THIS PROCEEDING

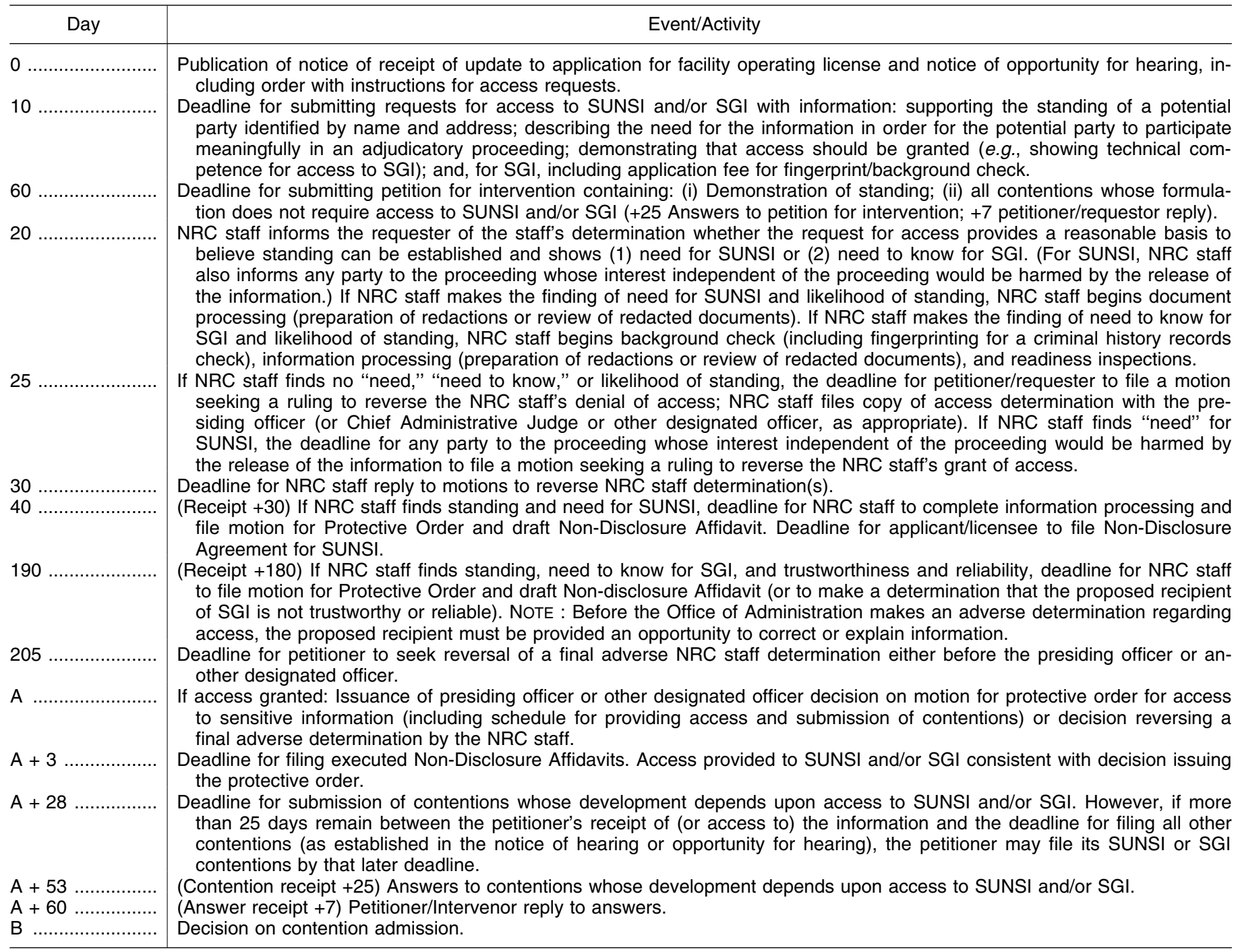

[FR Doc. E9-11903 Filed 5-21-09; 8:45 am] BILLING CODE 7590-01-P

\section{NUCLEAR REGULATORY COMMISSION}

[Docket No. 72-7-EA; ASLBP No. 09-88803-EA-BD01]

\section{Detroit Edison Company; Establishment of Atomic Safety and Licensing Board}

Pursuant to delegation by the Commission dated December 29, 1972 (37 FR 28710), and the Commission's regulations, see 10 CFR 2.106, 2.300, 2.313(a), and 2.318, notice is hereby given that an Atomic Safety and
Licensing Board (Board) is being established to preside over the following proceeding:

\section{Detroit Edison Company Fermi Power Plant}

\section{(Independent Spent Fuel Storage} Installation)

This proceeding concerns a Petition to Intervene dated May 7, 2009 from Beyond Nuclear, et al., that was submitted in response to an April 17, 2009 notice issued by the NRC Staff that provided the Issuance of Order for Implementation of Additional Security Measures and Fingerprinting for Unescorted Access to Detroit Edison Company (74 FR 17890).
The Board is comprised of the

following administrative judges:

Ronald M. Spritzer, Chair, Atomic

Safety and Licensing Board Panel,

U.S. Nuclear Regulatory Commission, Washington, DC 20555-0001.

Michael F. Kennedy, Atomic Safety and Licensing Board Panel, U.S. Nuclear Regulatory Commission, Washington, DC 20555-0001.

Randall J. Charbeneau, Atomic Safety and Licensing Board Panel, U.S.

Nuclear Regulatory Commission, Washington, DC 20555-0001.

All correspondence, documents, and other materials shall be filed in accordance with the NRC E-Filing Rule, which the NRC promulgated in August 2007 (72 FR 49139). 